Supporting Information

\title{
Poly(3,4-ethylenedioxythiophene) bearing phosphorylcholine groups for metal-free, antibody-free, and low-impedance biosensors specific for C-reactive protein
}

\author{
Tatsuro Goda*, Masahiro Toya, Akira Matsumoto, Yuji Miyahara* \\ Institute of Biomaterials and Bioengineering, Tokyo Medical and Dental University \\ 2-3-10 Kanda-Surugadai, Chiyoda, Tokyo 101-0062, Japan \\ *goda.bsr@tmd.ac.jp; miyahara.bsr@tmd.ac.jp
}




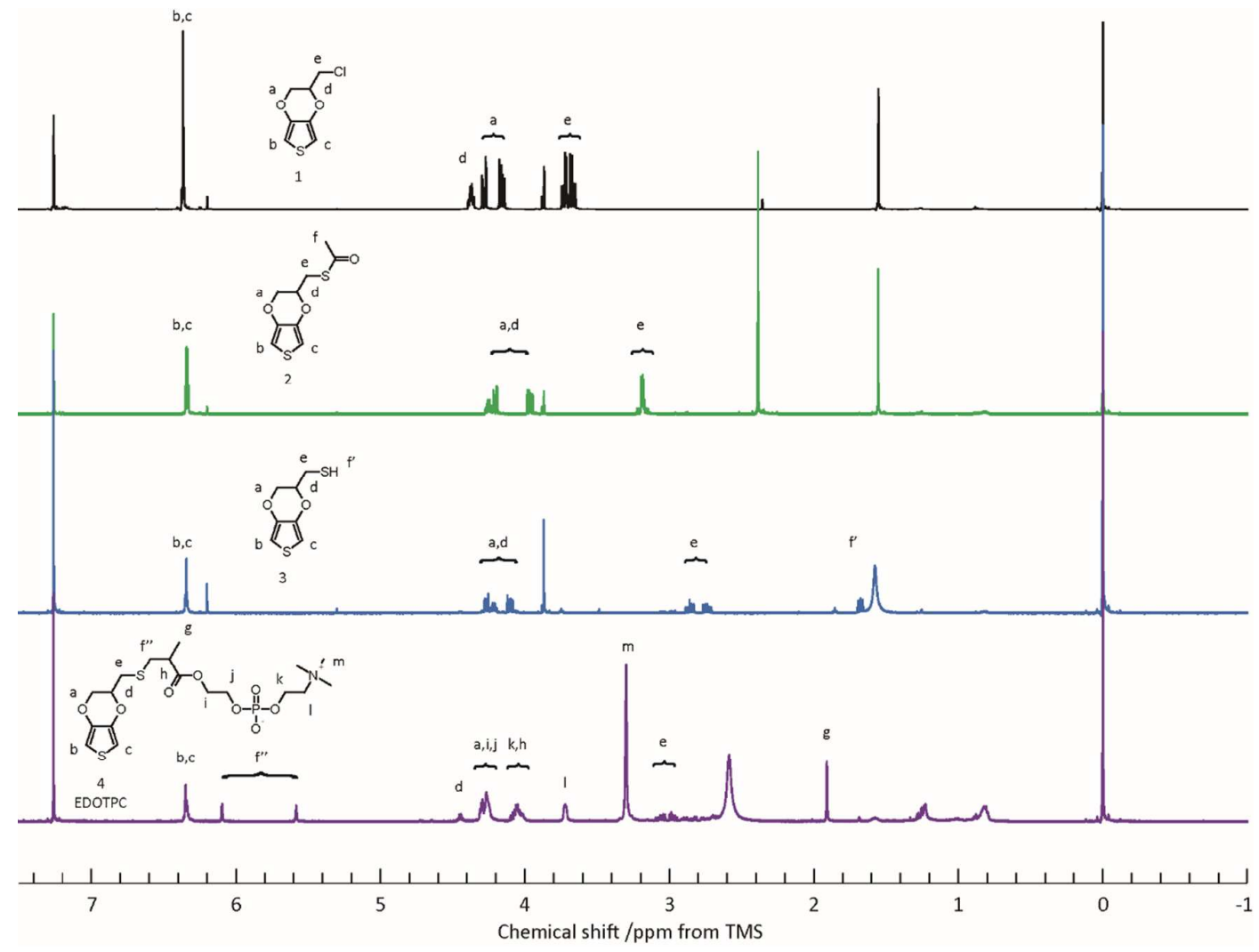

Figure S1. ${ }^{1}$ H-NMR spectra for chloromethyl-EDOT 1, EDOT-methanethioester 2, EDOT-methanethiol 3, and EDOTPC 4. $500 \mathrm{MHz}$ in $\mathrm{CDCl}_{3}$.

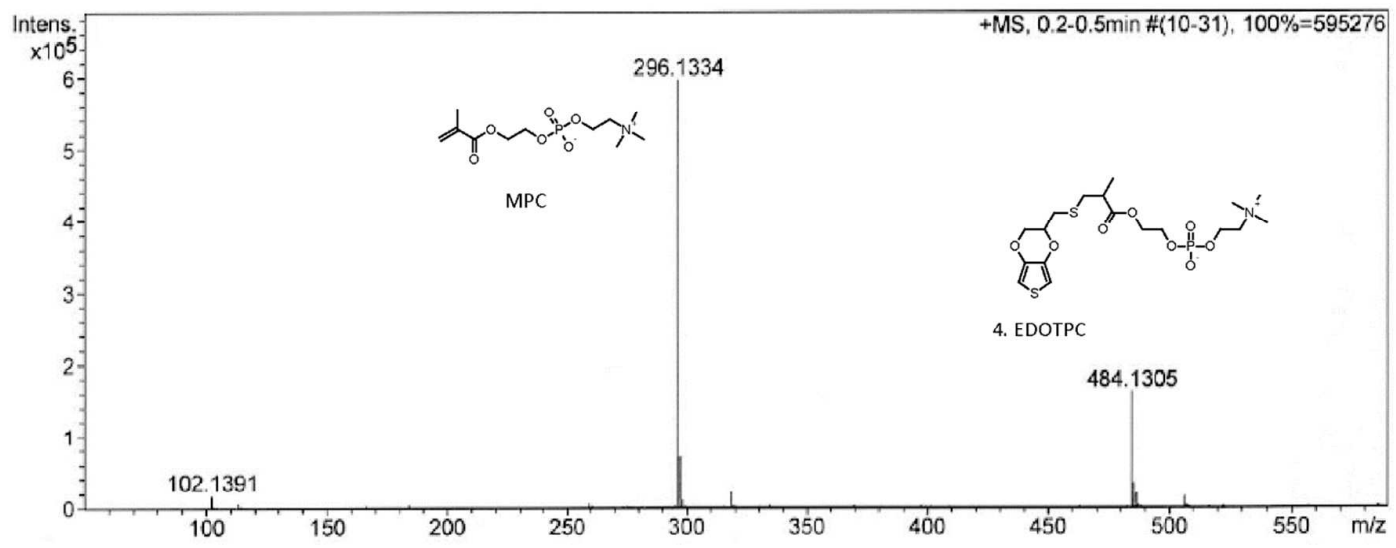

Figure S2. ESI-MS spectrum for EDOTPC 4 at positive mode. 

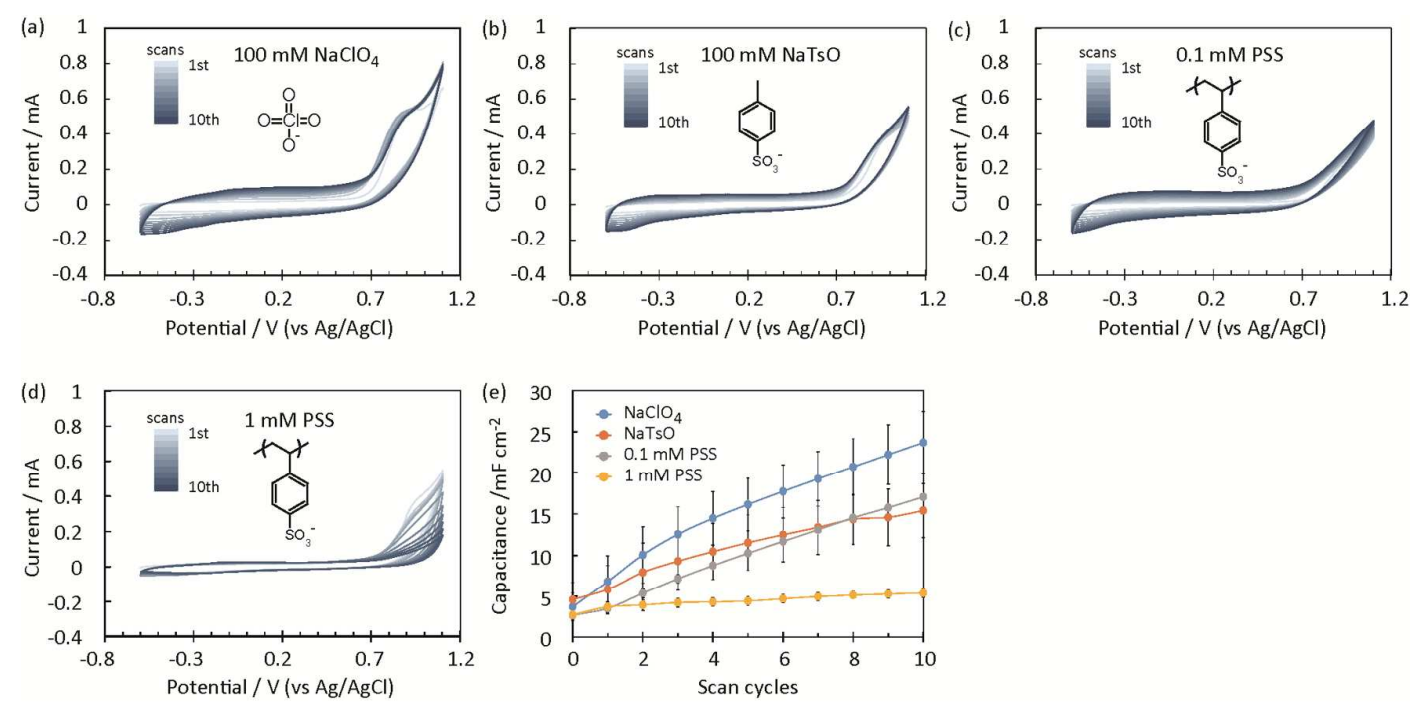

Figure S3. Cyclic voltammograms of glassy carbon electrodes in $10 \mathrm{mM}$ aqueous monomer solutions at 0 mol\% EDOTPC in feed composition with $100 \mathrm{mM} \mathrm{NaClO}_{4}$ (a), $100 \mathrm{mM}$ sodium $p$-toluenesulfonate $(\mathrm{NaTsO})(\mathrm{b}), 0.1 \mathrm{mM}$ poly(styrene sulfonate) (PSS) (c), or $1 \mathrm{mM}$ PSS (d). Counter electrode; Pt. Reference electrode; $\mathrm{Ag} / \mathrm{AgCl}$ (in $3.3 \mathrm{M}$ $\mathrm{KCl}$ aq). Scan rate; $0.1 \mathrm{~V} / \mathrm{sec}$. (e) Increases in the interface capacitance with $\mathrm{CV}$ cycles during the electropolymerization with different dopants.
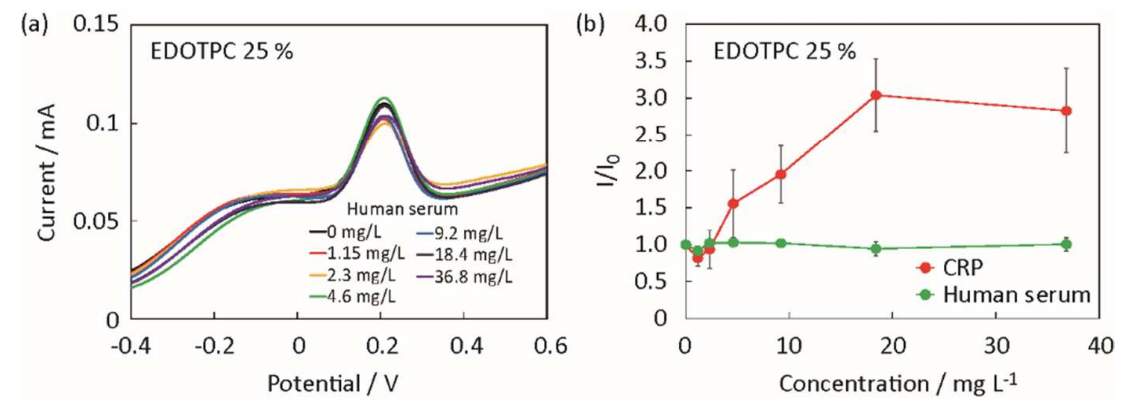

Figure S4. (a) DPV spectra of a conducting polymer film prepared at $25 \mathrm{~mol} \%$ EDOTPC on a glassy carbon electrode following the incubation with $0-36.8 \mathrm{mg} \mathrm{L}^{-1}$ human serum. (b) Changes in the ratio of peak currents in DPV spectra of the conducting polymer films prepared at $25 \mathrm{~mol} \%$ EDOTPC as a function of protein concentration. DPV was conducted in Hepes buffer solution $(10 \mathrm{mM}$ Hepes, $100 \mathrm{mM}$ $\mathrm{NaCl}, 1 \mathrm{mM} \mathrm{CaCl} 2 ; \mathrm{pH}$ 7.4) containing $5 \mathrm{mM}$ ferricyanide/ferrocyanide. Counter electrode: Pt, Reference electrode: $\mathrm{Ag} / \mathrm{AgCl}$ (in $3.3 \mathrm{M} \mathrm{KCl} \mathrm{aq).} \mathrm{Data} \mathrm{are} \mathrm{shown} \mathrm{as}$ average \pm standard deviation $(n=3)$. The concentration of serum proteins was determined by UV absorbance at $280 \mathrm{~nm}$ with BSA conversion. 
Table S1. Atomic compositions of the conducting copolymer films prepared at different compositions of EDOTPC during electropolymerization with $100 \mathrm{mM} \mathrm{NaClO} 4$ on planar gold electrodes determined by high resolution XPS. Unit: atom $\%$.

\begin{tabular}{|l|l|l|l|l|l|l|}
\hline Entry & $\mathrm{C}$ & $\mathrm{O}$ & $\mathrm{N}$ & $\mathrm{P}$ & $\mathrm{S}$ & $\mathrm{Au}$ \\
\hline EDOTPC 0 & 67.57 & 24.51 & 1.18 & 0.00 & 6.58 & 0.16 \\
$\mathrm{~mol} \%$ & \pm 0.78 & \pm 0.62 & \pm 0.17 & \pm 0.00 & \pm 0.14 & \pm 0.01 \\
\hline EDOTPC & 66.96 & 25.60 & 0.49 & 0.76 & 6.15 & 0.04 \\
$25 \mathrm{~mol} \%$ & \pm 0.60 & \pm 0.35 & \pm 0.25 & \pm 0.06 & \pm 0.24 & \pm 0.00 \\
\hline EDOTPC & 66.91 & 25.08 & 0.58 & 1.18 & 6.13 & 0.12 \\
$50 \mathrm{~mol} \%$ & \pm 0.70 & \pm 0.57 & \pm 0.16 & \pm 0.07 & \pm 0.23 & \pm 0.02 \\
\hline EDOTPC & 66.62 & 27.50 & 1.15 & 0.70 & 3.81 & 0.22 \\
$75 \mathrm{~mol} \%$ & \pm 0.63 & \pm 0.58 & \pm 0.29 & \pm 0.09 & \pm 0.23 & \pm 0.03 \\
\hline EDOTPC & 70.31 & 23.75 & 0.82 & 0.43 & 4.04 & 0.65 \\
$100 \mathrm{~mol} \%$ & \pm 1.40 & \pm 1.30 & \pm 0.29 & \pm 0.18 & \pm 0.32 & \pm 0.04 \\
\hline
\end{tabular}

